\title{
Wittgenstein y el escepticismo antiguo: desacuerdos, suspensión del juicio y persuasión*
}

\author{
Wittgenstein and ancient skepticism: \\ disagreements, suspension of judgment and persuasion
}

\author{
Guadalupe Reinoso \\ Grupo de investigación: Pirronismo y Neo-pirronismo \\ El influjo del escepticismo antiguo en la filosofía contemporánea \\ Universidad Nacional de Córdoba \\ Córdoba, Argentina \\ E-mail: guadareino@gmail.com \\ ORCID: 0000-0003-0003-5732
}

Fecha de recepción: 21 de junio 2018 Fecha de aprobación: 26 de febrero 2019 Doi: 10.17533/10.17533/udea.ef.n60a07

Resumen. Las discusiones recientes sobre las fuentes antiguas del escepticismo han proporcionado nuevos elementos para evaluar el alcance de la propuesta pirrónica y poder diferenciarla de las manifestaciones escépticas modernas. Esto, a su vez, ha permitido explorar la posibilidad de plantear afinidades entre las ideas que Sexto Empírico expuso en sus Hipotiposis Pirrónicas y las ideas que Wittgenstein presentó en Sobre la certeza. Mi propósito es evaluar el alcance de estas afinidades a partir del lugar que ambos autores otorgan a la problemática del desacuerdo.

Palabras claves: pirronismo, desacuerdos, suspensión del juicio, Wittgenstein, investigación gramatical, persuasión

\footnotetext{
* El presente trabajo es el resultado de las primeras investigaciones desarrolladas en el marco del Proyecto de Investigación bajo mi dirección titulado: "Pirronismo y Neo-Pirronismo: el influjo del escepticismo antiguo en la filosofía contemporánea" (2018-2022), proyecto subsidiado por la Secretaría de Ciencia y Tecnología de la Universidad Nacional de Córdoba, Argentina, (resolución SeCyT 472/18) y radicado en el centro de Investigaciones de la Facultad de Filosofía y Humanidades de la Universidad Nacional Córdoba. Agradezco a los evaluadores anónimos que designó el comité editorial por los comentarios críticos a la primera versión de este trabajo. Han resultado de mucha ayuda para la versión definitiva.
}

Cómo citar este artículo:

MLA: Reinoso, Guadalupe. "Wittgenstein y el escepticismo antiguo: desacuerdos, suspensión del juicio y persuasión". Estudios de Filosofia 60 (2019): 141-158.

APA: Reinoso, G. (2019). Wittgenstein y el escepticismo antiguo: desacuerdos, suspensión del juicio y persuasión. Estudios de Filosofia, 60, 141-158.

Chicago: Guadalupe Reinoso. "Wittgenstein y el escepticismo antiguo: desacuerdos, suspensión del juicio y persuasión". Estudios de Filosofia n ${ }^{\circ} 60$ (2019): 141-158. 


\begin{abstract}
Recent discussions about the ancient sources of skepticism have provided new elements to evaluate the scope of the Pyrrhonian proposal and to differentiate it from modern skeptical manifestations. This, in turn, has allowed us to explore the affinities between the ideas that Sextus Empiricus exposed in his Outlines of Pyrrhonism and the ideas that Wittgenstein presented in On Certainty. My purpose is to evaluate the scope of these affinities from the place that both authors give to the problem of disagreement.
\end{abstract}

Keywords: Pyrrhonism, disagreements, suspension of judgment, Wittgenstein, grammatical investigation, persuasion

\title{
1. Lecturas urbanas
}

En los últimos años, y a partir del debate que iniciaron Frede (1979), Burnyeat (1980) y Barnes (1982) sobre las fuentes antiguas del escepticismo, ${ }^{1}$ se ha explorado la posible vinculación entre el pirronismo y Wittgenstein (Fogelin, 1981, 1987, 1994; Marcondes, 1996; Sluga, 2004; Smith, 1993). Este debate centró la discusión sobre los límites de la suspensión del juicio en el pirronismo. La discusión planteó dos interpretaciones posibles: la interpretación rústica (Burnyeat, 1980; Barnes, 1982) que extiende la suspensión del juicio a todas las creencias; y la interpretación urbana (Frede, 1979, 1984) que delimita la suspensión del juicio a los dogmas filosóficos, dejando intactas las creencias que provienen de la experiencia fenoménica. Las lecturas que acercan, especialmente, las reflexiones de la última etapa de la vida de Wittgenstein siguen la interpretación urbana del pirronismo.

En las reflexiones publicadas póstumamente bajo el título de Sobre la certeza (1969), Wittgenstein analiza la apelación de G. E. Moore al sentido común como una estrategia contra el escepticismo que niega el conocimiento del mundo externo. Las discusiones históricas sobre las fuentes antiguas del escepticismo muestran que la versión negativa radical del escepticismo procede de la modernidad (especialmente de la recepción y original utilización cartesiana de los argumentos escépticos clásicos) y se diferencia de las primeras manifestaciones, especialmente del pirronismo. ${ }^{2}$ Las reflexiones de Wittgenstein sobre las creencias del sentido común, sobre cómo son transmitidas y adquiridas, y sobre los conceptos y proposiciones

1 Para mayores destalles de este debate se puede consultar Burnyeat and Frede (1997).

2 Robert Fogelin (1994) distinguió entre un escepticismo filosófico y un escepticismo sobre la filosofía para presentar las diferencias entre la versión cartesiana y la versión de Sexto Empírico. En estos términos el pirronismo toma a la filosofía como el objetivo de su crítica. Para ello, utiliza argumentos filosóficos que se refutan a sí mismos (véase Fogelin, 1994, p. 3) sin cuestionar las creencias del sentido común. Esta distinción se basa en una interpretación urbana del pirronismo que es la que le permite a Fogelin explorar las afinidades entre Wittgenstein y Sexto Empírico. 
que utilizamos para referirnos a ellas, parecen estar en sintonía con muchas de las ideas que Sexto Empírico plasmó en sus Hipotiposis Pirrónicas. ${ }^{3}$

Así el escepticismo moderno o cartesiano queda caracterizado por una radicalidad derivada del uso hiperbólico de la duda que extiende la incertidumbre a todas nuestras creencias, incluidas las cotidianas. Por el contrario, y siguiendo la interpretación urbana, en los pirrónicos la labor corrosiva de los tropos (HP I. 31-186) no asume este modo radical ya que el asentimiento a los fenómenos, a las exigencias vitales, se nos impone (HP I. 19-24). Siguiendo esta interpretación se puede decir que, si bien Wittgenstein critica al escéptico cartesiano, su postura general no puede ser descripta como anti-escéptica. Uno de los argumentos principales para sostener esta lectura es remarcar, en primer lugar, la condición que el austríaco establece para las dudas: éstas, para tener sentido, deben sostenerse en razones (SC $\S 4,24,37,122,126,255,450$, entre otros parágrafos) y para dudar primero debo creer (SC $\$ 217-222,229,519$, entre otros); la duda presupone certeza (SC §115). De este modo, no se puede plantear una duda que evalúe, de una vez, todo nuestro sistema de creencias como pretendió Descartes en su primera meditación metafísica (1641). Pero, y en segundo lugar, demarcado este límite para la duda, en Sobre la certeza también se delimitan los alcances de la evaluación racional de nuestras creencias: los compromisos más profundos, nuestros acuerdos más básicos, las llamadas proposiciones bisagras (SC §341, 342; también §96, 136), por la función que cumplen en nuestro entramado de creencias, son inmunes a la evaluación epistémica: "Pero no tengo mi imagen del mundo porque me haya convencido a mí mismo de que sea la correcta; ni tampoco porque esté convencido de su corrección. Por el contrario, se trata del trasfondo que me viene dado y sobre el que distingo entre lo verdadero y falso" (SC § 94; cf. 95-100; 136-138, 144, 166, 253). Esta manera de reinterpretar, en definitiva, los alcances y límites de nuestra racionalidad que Wittgenstein despliega es el punto a partir del cual se trazan afinidades significativas con la crítica al dogmatismo filosófico y el asentimiento no voluntario a los fenómenos (HP I.19-24) que esboza la orientación pirrónica.

Ahora bien, aceptada esta afinidad entre Wittgenstein y el proceder filosófico del pirronismo en el modo en que, frente a nuestros acuerdos más básicos, ambos muestran que no pueden exigirse razones o justificaciones, aunque tampoco pueden

3 La edición que utilizaremos para las citas de las Hipotiposis Pirrónicas (HP) será la de Akal (1996), con la indicación del número de libro (I, II o II) seguido de un punto y el número de línea correspondiente. 
ponerse en duda, parece surgir una discrepancia en la actitud que adoptan frente a un tópico central del pirronismo: los desacuerdos. En las líneas iniciales de las Hipotiposis, Sexto presenta los principios de la skepsis que busca alcanzar la imperturbabilidad [ataraxia] ya que

los grandes talentos, confundidos por el carácter contradictorio de las cosas y dudosos respectos a cuáles de ellas mejor asentir, se vieron abocados a indagar qué es lo verdadero y qué lo falso, buscando alcanzar, a través de este examen, la imperturbabilidad (HP I. 12).

Para Porchat (1991) la experiencia de la diaphonía - la discordancia, el desacuerdo - se da en el común de los hombres y se potencia "de mil modos sofisticados" en las disputas filosóficas. Sobre nada parece ponerse de acuerdo los filósofos, "ni siquiera sobre el objeto, la naturaleza o el método del propio emprendimiento de filosofar" (Porchat, 1991, p. 1, mi traducción). ${ }^{4}$ Sexto caracteriza al desacuerdo unas líneas más adelante como uno de los tropos que nos lleva a la epoché:

descubrimos que se da una irresoluble disputa, tanto entre la gente ordinaria como entre los filósofos, acerca del objeto propuesto; por lo que, al no poder elegir o rechazar nada, concluimos en la suspensión del juicio (HP I. 165). ${ }^{5}$

Puede trazarse entonces una distinción entre una primera experiencia de la diaphonía en nuestra vida cotidiana que lleva a algunos hombres a la indagación filosófica y una segunda experiencia en el ámbito de la filosofía que, dada la equipolencia propuesta entre las razones y argumentos, resulta, provisoriamente, una diaphonía irresoluble porque no es posible inclinar la balanza por ninguna de las posiciones en disputa.

Wittgenstein también trata el problema de los desacuerdos en Sobre la Certeza pero adopta, desde mi lectura, una estrategia diferente a la suspensión del juicio

4 Porchat comparte dos ideas con Fogelin (1994): la distinción entre el escepticismo cartesiano y el escepticismo de Sexto y la restricción de la suspensión del juicio sólo a las tesis filosóficas. Ambos, Porchat y Fogelin, se llaman neo-pirrónicos, principalmente, porque adoptan una interpretación urbana del pirronismo. Siguiendo a Frede, Porchat y Fogelin entienden que los pirrónicos no vacilan en dar su asentimiento a las creencias de la vida común y problematizar solo las creencias que están racionalmente justificadas.

5 El tropo del desacuerdo es uno de los cinco tropos — el regreso al infinito, con relación a algo, el por hipótesis y el circulo vicioso- que "los escépticos más recientes" (HP I. 164) han formulado. Estos cinco tropos de Agripa conforman diversos recursos, entre otros, de los que el escéptico se sirve para combatir al dogmático. 
pirrónica. Para Wittgenstein una vez agotada la habilidad de ofrecer razones no se suspende el juicio, sino que parece haber lugar para el uso de otra habilidad: la persuasión. Aquí debemos recordar que la terapéutica filosófica que Wittgenstein propone tiene como uno de sus propósitos modificar el modo de ver el problema que tiene el interlocutor con el que disputa. Más que refutar a su oponente a través de la elaboración de respuestas argumentativas alternativas, lo que se pretende es un cambio de perspectiva, un cambio de enfoque, que lleve a una disolución del problema. Baker (2004) remarca esta caracterización indicando que Wittgenstein ofrece un método para tratar a los pensadores y sus dificultades [troubles], no problemas [problems], confusiones o sinsentidos abstractos. Citando el Cuaderno azul señala: "La misma palabra "problema" [problem], alguien podría decir, se aplica mal cuando se usa para nuestras dificultades [troubles] filosóficas" (Baker, 2004, p. 181). Por otra parte, y como veremos a continuación, el desacuerdo en el marco de Sobre la certeza se vincula también con nuestra capacidad limitada para justificar nuestras creencias más básicas (SC §166, 189, 192).

§262: Puedo imaginarme un hombre que hubiera crecido en unas circunstancias especiales y a quien se le hubiera dicho que la tierra apareció hace 50 años y que por lo tanto lo creyera. Podríamos enseñarle: la Tierra existe desde hace... etc. Trataríamos de darle nuestra imagen del mundo. Tal cosa sucedería por medio de la persuasión [Art Überredung].

Aquí la apelación a la persuasión frente al desacuerdo parece acentuar la idea de la limitación en la práctica de ofrecer razones para esta clase de creencia ya que, por un lado, ellas no son producto de una investigación (SC §138) y, por el otro, no podemos decir con claridad cómo las obtenemos (SC § 84, 87). ¿Esta apelación a la persuasión por parte de Wittgenstein negaría o se opondría a la suspensión del juicio planteada por el pirrónico? Para ponderar las diferencias entre la estrategia esgrimida por Wittgenstein y la de los pirrónicos sextianos, debemos considerar tres de los elementos que la suspensión del juicio parece exigir: 1) un escenario dogmático estable que delimita un espacio argumentativo-dialéctico en el que se equiparan la fuerza y el peso lógico de las razones; 2) la idea de desacuerdos irresolubles porque no se cuenta con un criterio de verdad que los resuelva; 3 ) un modo de entender la filosofía como la búsqueda de la verdad que determina el modo de entender los problemas filosóficos. Wittgenstein, no parece suscribir a una perspectiva semejante: 1) no acepta el escenario que le plantea el dogmático en la búsqueda de equipolencia, ya que no sólo despliega estrategias en un escenario argumentativo, sino también da lugar al uso de herramientas persuasivas; 2) no se 
establece una exigencia de un criterio de verdad para enfrentar los desacuerdos que resultan irresolubles; 3) el desafío es entender a la filosofía no como la búsqueda de la verdad, sino como investigación gramatical que disuelve problemas porque estos son producto de confusiones o enredos lingüísticos de personas concretas. Esas confusiones no son tratadas como meros errores lingüísticos u opiniones falsas a ser refutadas de modo estrictamente argumentativo; por el contrario, son interpretadas como un efecto de la vaguedad y flexibilidad característica de nuestros usos del lenguaje pero también como el efecto de no comprender cómo operan inconscientemente $^{6}$ en nosotros nuestros prejuicios.

De esta forma, se establece una divergencia con el proceder filosófico desplegado por el pirronismo no sólo en el modo de entender el papel asignado a las razones, a la argumentación y a la persuasión en las controversias filosóficas, sino también en la capacidad real que tendría un sujeto, a partir de la disputa dialéctica-argumentativa, para "abstenerse" de creer y afirmar. Cabe señalar que mi intención no es cuestionar la riqueza que han proporcionado las lecturas que acercan a Wittgenstein al pirronismo, sino más bien que ellas han pasado por alto diferencias importantes, por lo que corren el riesgo de forzar en exceso el acercamiento planteado. Considero que cuando se exploran detenidamente las diferencias entre ambas propuestas se puede seguir sosteniendo una lectura escéptica -0 antidogmática- de los textos de Wittgenstein pero más ajustada a las especificidades de su propuesta metodológica que evita caer en anacronismos. Analicemos algunos de los puntos de divergencia entre Sexto Empírico y Wittgenstein.

\section{Escenarios dogmáticos}

Lo primero que podemos preguntar es a qué clase de desacuerdos se refiere el pirrónico sextiano bajo una interpretación urbana. Hay desacuerdos cotidianos en el ámbito de lo fenoménico, por ejemplo sobre el color o la forma de un objeto, que son, en principio, normalmente fáciles de resolver. Bastaría acercarnos a los objetos para corroborar su forma, o bajo una luz adecuada verificar su color. Esta clase de desacuerdo no parece representar un desafío escéptico serio para nuestras creencias. El desafío crucial que nos plantea el pirrónico proviene de

6 La elección de este término es deliberada y remarca el aire de familia entre la terapéutica propuesta por Wittgenstein con algunos aspectos de la noción de terapia de Freud. Para mayores detalles de esta comparación se puede consultar Bouveresse (2004) y Baker (2004). Ver en este mismo texto la nota $\mathrm{n}^{\circ} 15$. 
los desacuerdos que en principio no pueden ser resueltos. Sexto nos interpela con el desafío que plantean los desacuerdos irresolubles entre los filósofos sobre la naturaleza de la realidad.

Cuando los pirrónicos hablan de esta clase de desacuerdos no se refieren a que sean irresolubles sólo porque uno de los participantes pueda resultar irracional, deshonesto o incompetente. Existen disputas filosóficas en las que no se presentan estos "vicios epistémicos". Admitimos que los participantes están bien informados y son igualmente buscadores de la verdad, racionalmente competentes, sinceros $\mathrm{y}$, sin embargo, el desacuerdo persiste. El pirronismo propone para los escenarios de disputa filosófica la habilidad de argumentar de los dos lados de una cuestión - existen buenas argumentos a favor de $p$ y buenos argumentos a favor de $\sim p$ muestra la equivalencia de fuerza entre argumentos discordantes provocando la anulación mutua. Por ello, frente al desacuerdo filosófico se sigue la suspensión del juicio. ${ }^{7}$

La presentación ofrecida por Sexto sobre la equipolencia (isostheneia), el equilibrio entre fuerzas opuestas equiparadas de los argumentos en disputa, permite distinguir tres aspectos diferentes. El primero da cuenta de cierta restricción psicológica:

No empleamos la expresión <argumentos opuestos> en el sentido de afirmaciones y negaciones, sino en el más simple de $<$ razones enfrentadas $>$. Llamamos <equivalencia> [isostheneia] a la igualdad de probabilidad [credibilidad] e improbabilidad [incredibilidad], de manera que ninguno de los argumentos en conflicto se anteponga a otra como si fuera más convincente (HP I. 10).

Sin embargo, Sexto no relaciona la equipolencia entre los argumentos sólo a la cuestión psicológica ${ }^{8}$ de la equivalencia en la plausibilidad — los grados de credibilidad o convicción — de las razones enfrentadas. Más bien, y aquí el segundo

7 Para Machuca la discusión actual sobre el significado epistémico del desacuerdo se centra casi exclusivamente en la disputa entre pares epistémicos "dejando grandes cuerpos intactos de nuestras creencias. Por lo tanto, el tipo de escepticismo agnóstico encontrado en la literatura sobre el desacuerdo tiene poco que ver con el escepticismo agnóstico radical adoptado por los antiguos escépticos pirrónicos, quienes suspendieron el juicio en todos los ámbitos sobre la base de argumentos aplicables a cualquier tipo de desacuerdo" (Machuca, 2013, p. 10). En este trabajo que sigue la interpretación urbana (no radical) del pirronismo, me interesa centrarme sólo en las controversias irresolubles dadas en los escenarios dogmáticos (filosóficos) y cómo se postula allí la suspensión del juicio.

8 Para destacar el aspecto psicológico Sexto acentúa la relación de los desacuerdos con la angustia, la perturbación, la confusión y ansiedad, etc. (HP I. 12). 
aspecto exigido, como participantes en la disputa no debemos anteponer nuestras propias apariencias o juicios sobre los de los demás participantes ya que resulta una petición de principio. Así puede entenderse la recomendación del segundo tropo "Según la diferencia entre los hombres":

Ciertos dogmáticos petulantes [filotoi, que se aman a sí mismos] afirman que, al emitir juicio sobre estas cuestiones, se les debería otorgar razón frente a los demás, sabemos que su pretensión es absurda, pues ellos mismos son parte de la controversia y, si juzgaran las apariencias atribuyéndose la razón, dirimirían el litigio a su favor escamoteando la cuestión antes de comenzar su examen (HP. I 90).

Aquí la condición exigida es epistémica, en tanto investigador de la verdad, en tanto zetético, no es racional, en el sentido de no estar justificado racionalmente, sostener mi juicio como verdadero ya que todavía no se ha demostrado que se base en algo más que en mi propia experiencia fenoménica. Este aspecto se relaciona con el último que se refiere al problema del criterio, no podemos al mismo tiempo ser parte y juez de la disputa:

Pues no podemos decidir entre nuestras propias percepciones y las de otros animales, desde el momento en que somos parte del litigio y estamos, por consiguiente, más necesitados de juez que capacitados para juzgar nosotros mismos (HP I. 59).

(...) para poseer un criterio aceptado, la disputa por el criterio debe ser primero dirimida. Ahora bien, incurriendo así la argumentación en el tropo del razonamiento circular, el descubrimiento del criterio resulta impracticable: pues no les concederemos la adopción de un criterio por hipótesis y, si pretenden juzgar un criterio con otro criterio les forzaremos [a los dogmáticos] a una regresión al infinito. Además, puesto que la demostración requiere un criterio demostrado, mientras el criterio requiere una demostración probada, incurren en el tropo del razonamiento circular (HP II. 20).

El problema del criterio pone de manifiesto que la noción de desacuerdo es provisoriamente irresoluble porque ninguna de las partes tiene razones o juicios concluyentes para convencer a la otra. La idea de criterio de verdad no niega que en el ámbito doxástico o fenoménico pueda ser prácticamente racional para mí sostener una creencia aun cuando no tenga una razón epistémica para hacerlo, ni niega tampoco que pueda ser psicológicamente imposible renunciar a ella. Sin embargo, en tanto filósofo que busca la verdad no debo afirmar mi creencia 
hasta obtener un criterio que permita superar la divergencia. Para Lammenranta (2016) este escenario filosófico en el que se dirime el desacuerdo es un escenario dogmático argumentativo que supone una teoría de la justificación "dialéctica" donde $S$ está justificado a creer que $p$, si y sólo si $S$ puede defender $p$ contra los desafíos apropiados. De acuerdo con este tipo de teoría para estar justificados en mi creencia, debo ser capaz de defender argumentativamente mi creencia de las objeciones que otra persona haga, es decir, sólo puedo sostenerla si tengo razones o pruebas para convencer a la otra parte (Lammenranta, 2016, p. 9).

Pero cabe aquí una aclaración, no es que el pirrónico defienda una teoría de la justificación determinada. En sentido estricto, los escépticos antiguos no defienden una posición propia, argumentan generalmente ad hominem. Sí puede sostenerse, en cambio, que su intención es mostrarle al dogmático que en su propio escenario argumentativo-dialéctico no puede determinarse el criterio de verdad que suponen, esto es, no puede cumplirse con las exigencias que ellos mismos reclaman para dirimir los desacuerdos. Al no poder establecerse dicho criterio, los desacuerdos resultan irresolubles por lo que se suspende el juicio.

Consideremos ahora el caso de Sobre la certeza. Wittgenstein distinguen clases de desacuerdos, en SC $\$ 108$ menciona los siguientes:

'Pero ¿entonces no hay verdad objetiva? ¿No es ni verdadero ni falso que alguien ha estado en la luna?' Si estamos pensando dentro de nuestro sistema, entonces es cierto que nadie ha estado jamás en la luna. No sólo nunca algo de esa naturaleza nos ha sido comunicado seriamente por gente razonable, sino que nuestro sistema entero de física nos prohíbe creerlo. Pues ello exige respuestas a las preguntas: ¿Cómo se sustrajo a la fuerza de gravedad? ¿Cómo podría vivir sin atmósfera?, y a otras mil, que no podrían ser contestadas. Pero, supóngase que, en lugar de todas esas respuestas, encontráramos esta réplica: 'No sabemos cómo se llega a la luna, pero los que llegan saben inmediatamente que se encuentran allí; y sin embargo, no puedes explicarlo todo'. Nos sentiríamos intelectualmente muy distantes de quien dijera esto. ${ }^{9}$

9 Wittgenstein (SC): $\S 608$ : “ ¿Es un error que me rija en mis acciones por las proposiciones de la física? ¿He de decir que no tengo ninguna buena razón para hacerlo? ¿No es esto precisamente lo que llamamos una ‘buena razón'?”; §609: “Supongamos que encontramos gente que no considere eso como una razón concluyente. Ahora, ¿cómo nos imaginamos esto? En lugar de al físico, ellos consultan un oráculo (y es por ello que los consideramos primitivos). ¿Es erróneo que consulten un oráculo y se guíen por él? -Si llamamos a esto 'erróneo' ¿no partimos ya de nuestro juego de lenguaje para combatir el suyo?”; §610: “¿Y estamos o no en lo correcto al combatirlo? De hecho apoyaremos nuestra acción 
Lo que se desprende de esta cita son grados diferenciados de discrepancia en las que en ningún caso parece postulase la suspensión del juicio. En un extremo, estarían los desacuerdos profundos que surgen por no compartir un mismo sistema de creencias - ya sea una cultura radicalmente diferente o casos de locura. En esta situación, no hay espacio para una controversia argumentativa porque no habría un marco común para dirimir la disputa. Por ello no puede adoptarse la suspensión del juicio porque no sería posible establecer la equipolencia entre argumentos, condición que exige la abstención propuesta por Sexto. En el otro extremo, se plantean los desacuerdos entre personas con las que compartimos un mismo sistema de creencias. En este caso, se establece un espacio común no sólo para evaluar racionalmente las creencias sino también aquellos elementos a los que se apela para ponerlas en duda. Wittgenstein, siguiendo las intuiciones de Moore, invierte la carga de la prueba, antes de poner en suspenso mi creencia exijo razones suficiente que justifiquen las dudas o desafíos que se plantean en contra de ella. Hasta aquí, podríamos decir que en términos clásicos estamos aún en el ámbito de lo fenoménico y no parece trazarse una diferencia sustancial entre Wittgenstein y Sexto sobre los desacuerdos en este ámbito.

Analicemos ahora un ejemplo de desacuerdo irresoluble filosófico. Admitamos posiciones filosóficas opuestas sobre, por ejemplo, qué es el tiempo. Los estoicos, dicen que "el tiempo es la duración del movimiento del [Todo] Universo" (HP III. 136-38). Otros, que es el propio movimiento del Mundo. Aristóteles 1 tiempo es "la numeración del antes y del después, en el movimiento" (HP III. 136-38). Para el pirrónico, luego de sopesar todos los argumentos y contra-argumentos, se suspende el juicio, dejando dicho desacuerdo irresuelto. Wittgenstein parece adoptar una estrategia diferente, no sopesa las diferentes respuestas a este problema, sino que revisa el modo en que ha sido formulada la pregunta. La estrategia de Wittgenstein es mostrar lo desorientada que resuelta la pregunta ¿qué es el tiempo? porque hace que busquemos una definición que nunca obtenemos. Fogelin (1994) encuentra afinidades entre el enfoque terapéutico de Wittgenstein y los procedimientos del pirrónico, en particular en la abstención a realizar afirmaciones por sí mismo, como

con todo tipo de frases hechas [slogans]"; §611: "Donde se encuentran dos principios irreconciliables entre sí, entonces cada cual dice del otro que es un loco y un hereje"; §612: "Dije que 'combatiría' al otro - pero, ¿no le daría razones? Seguro; pero, ¿cuán lejos alcanzan? Al final de las razones está la persuasión [Überredung]. (Piensa en lo que sucede cuando los misioneros convierten a los nativos)". 
a las críticas internas a las pretensiones dogmáticas por afirmar tesis filosóficas. ${ }^{10}$ Pese a esta afinidad, la terapéutica propuesta por Wittgenstein no se centra en descubrir y señalar las debilidades o inconvenientes en los argumentos de su oponente (en el caso del tiempo, su oponente es San Agustín, ver el Cuaderno Azul), sino que busca que el oponente perciba cómo llegó, a partir de una confusión o desvío, a establecerse el problema. ${ }^{11}$ Para ello se sirve de una gama muy amplia de estrategias estilísticas destinadas a operar un cambio en el modo de ver la cuestión aparentemente problemática (cf. Burdman, 2016).

Wittgenstein, como ya indicamos, pretende llevar a su oponente a cambiar su estilo de pensar los problemas filosóficos, intenta mostrar la fuerza que puedan llegar a tener ciertas imágenes, metáforas, ciertos modos de expresarse, ciertos recursos estilísticos y retóricos como medios para tratar de conducir a alguien a cambiar su modo de ver y valorar algo. La idea subyacente en esta estrategia es que adoptamos y sostenemos ciertas perspectivas filosóficas no porque tengamos argumentos o razones a favor de su verdad o validez, sino, más bien, porque nos seduce, porque ejercen sobre nosotros cierta fascinante perplejidad. De ahí que la persuasión resulte más poderosa que los argumentos explicativos-causales por medio de razones, o las justificaciones, ya que lo que se combate es la seducción que ciertas imágenes ejercen sobre nosotros. ${ }^{12}$

10 Pierre Hadot sugiere incorporar a Wittgenstein en la tradición que asume a la filosofía como un modo de vida. Se puede consultar: Hadot (2009).

11 SC $\$ 37$ : “ ¿es una respuesta satisfactoria al escepticismo del idealista o a las aseveraciones del realista (decir que la proposición) 'existen objetos físicos' no tiene sentido? (...) una respuesta podría ser: tal aserción, o su contraria, no es sino un intento frustrado de expresar lo que no puede expresarse de este modo".

12 Dado el contexto de discusión sobre el escepticismo es relevante mencionar una diferencia entre este concepto de fascinación y el de los modernos. Para la filosofía moderna los fanáticos eran los supersticiosos típicos: en general, los fanáticos religiosos. La superstición actúa inflamando los vapores o las pasiones y hace que el fanático abrace las hipótesis más extravagantes. La idea o noción de fascinación viene de la mano con la de un arrebato, de algo que sobreviene. Si bien Wittgenstein también habla de superstición en el marco de las discusiones religiosas, la fascinación describe otros fenómenos: especialmente la adopción del modelo científico como modelo explicativo filosófico. En este caso, la clave interpretativa para la fascinación en filosofía parece ser freudiana: algo que atrae, seduce y al mismo tiempo genera perplejidad. Puede decirse que debido a esta clase de fascinación los filósofos, por querer mantenerse en ella, convierten lo simple y ordinario en algo complejo y misterioso. Por eso cuando se cambia la forma de ver el asunto que nos inquieta "la niebla se disipa", lo que era un problema simplemente deja de serlo, se disuelve. 


\section{Argumentación y persuasión}

Apreciar el papel otorgado a la persuasión resulta central para comprender aspectos de la orientación filosófica de Wittgenstein. Si, como señala en diversas ocasiones, las razones llegan a su final, si no se puede ir más allá o avanzar en una discusión con ellas, no necesariamente quedamos condenados al silencio, pues aún es posible recurrir a la persuasión (cf. Meléndez, 2003, p. 192). A pesar del lugar destacado que la persuasión ocupa en los escritos de Wittgenstein, no negamos que recurra a diversos procedimientos que, en un sentido amplio, no-técnico, cabe considerar 'argumentativos' ( $c f$. Burdman, 2016). Nuestro autor caracteriza su enfoque en las Lecciones sobre estética a partir del contraste clásico entre argumentación y persuasión:

He llamado su atención en numerosas ocasiones sobre determinadas diferencias; por ejemplo, en estas clases he intentado mostrarles que la infinitud no es tan misteriosa como parece. Lo que estoy haciendo es también persuasión. Si alguien dice: "no hay diferencia", y yo digo "hay una diferencia", estoy persuadiendo, estoy diciendo "no quiero que vean esto de ese modo" (...). En cierto sentido, estoy haciendo propaganda en favor de un estilo de pensamiento y en contra de otro. Sinceramente, el otro me produce aversión. También estoy tratando de exponer lo que pienso. Sin embargo estoy diciendo: "por amor de Dios, no hagan eso" (Wittgenstein, $1966, \S \S 35-37) .^{13}$

Esta referencia al objetivo de Wittgenstein como un objetivo de persuasión merece una ampliación ya que la persuasión desde cierta tradición — especialmente la platónica en su disputa con los sofistas - ha sido pensada como "una forma ilegítima de argumentación o, en todo caso, como una forma no-argumentativa (no abierta a crítica) de producir efectos sobre el otro" (Burdman, 2016, p. 15). En este marco la persuasión debe ser entendida como un conjunto de procedimientos cuyo objetivo principal es operar un cambio sobre nuestro modo de percibir las cuestiones que nos generan cierta perplejidad por ser aparentemente problemáticas. El tipo de

13 De un modo similar sugiere en Cultura y Valor: "Un filósofo dice “¡mira a las cosas así!” —pero en primer lugar, eso no asegura que la gente vaya a mirar las cosas de esa manera, y en segundo lugar su admonición puede estar llegando completamente tarde; es posible, además, que tal admonición no pueda conseguir nada en ningún caso y que el impulso para tal cambio en la manera en que las cosas son percibidas tenga que originarse en otro lado enteramente diferente" (Wittgenstein, 1998, p. 70). También en SC §610: “¿Y estamos o no en lo correcto al combatirlo? De hecho apoyaremos nuestra acción con todo tipo de frases hechas (eslóganes)". 
cambio que interesa que se origine es uno que no podría operarse mediante la defensa directa de una serie de tesis (a favor o en contra) acerca de la filosofía o acerca de algún problema filosófico concreto.

Como también indica Burdman, los límites de lo argumentable como problemática epistémica es uno de los tópicos más importantes en el desarrollo de Sobre la certeza. El análisis sobre la adquisición de creencias y de cómo damos cuentas de ellas permite iluminar el contraste que se establece entre argumentación y persuasión que parece mantenerse desde los escritos de la etapa de transición (1929-1935) hasta las redacción de las notas que conforman su último escrito (19491951). La capacidad para argumentar a favor de nuestras creencias tiene límites ya que la exigencia de razones no puede extenderse a todas nuestras creencias: algunas de ellas se aceptan sin justificación y otras exigen razones y argumentos para sostenerlas. Son los contextos lingüísticos los que determinan las movidas lingüísticas que se aceptan y las que no. Wittgenstein advierte que la capacidad para argumentar se despliega en un marco lingüístico común; si ese marco no es compartido o disputamos la inadecuación del marco del oponente, nuestra capacidad para ofrecer razones llega a su fin con rapidez. Es decir, las razones son buenos argumentos cuando son ofrecidas en una conversación con alguien que acepte el marco de referencia que nuestra posición está suponiendo. ${ }^{14}$

Agotada la posibilidad de dar y pedir razones en la discusión filosófica se da lugar al uso de la "propaganda" entendida como la búsqueda de convertir a nuestro interlocutor a nuestro modo de ver la cuestión, a nuestro modo de ver el mundo e instarlo a adoptar nuestro modo de usar el lenguaje (SC§ 92). Esta conversión no debe entenderse en términos refutatorios o a través de la comprobación de la falsedad del punto de vista que defiende nuestro oponente, sino como un cambio, como el intento de llevar a nuestro interlocutor a ver el asunto en disputa bajo otra luz. Pero ¿cuándo se produce este cambio? ¿Cuándo se produce el "clic" — para utilizar la expresión de la que Wittgenstein se sirve en las Lecciones sobre estética-? Se produce cuando súbitamente a quién intentamos persuadir se siente satisfecho con nuestra manera de ver y hacer ver el fenómeno que se quiere comprender; cuando se acepta y adopta la imagen que se presenta. ${ }^{15}$

14 Este es uno de los tópicos con el que da apertura las reflexiones en sus Conversaciones sobre creencia religiosa: qué clase de desacuerdo se establece entre un creyente y un no creyente.

15 Pero no es que se dé con la explicación correcta o definitiva. Aquí persuadir debe entenderse en el sentido de llevar a alguien a ver el fenómeno de cierta manera que es aceptada y adoptada por él, que lo deja satisfecho. En relación con estas reflexiones, Wittgenstein indica la cercanía de su propuesta 


\section{Los problemas filosóficos}

Los pirrónicos sextianos ofrecen argumentos dogmáticos en favor de ambos lados de la disputa, procurando equilibrar las dos caras de una cuestión, así sus argumentos parecen situarse en un plano estable y estrictamente dialéctico de argumentación. En consecuencia, el pirronismo antiguo sería el resultado de — la reacción contra — una postura dogmática, de una forma dogmática de plantear las cuestiones en filosofía. Los pirrónicos, en primera instancia, no desacuerdan con los dogmáticos en el modo de entender los problemas filosóficos. Para Wittgenstein, por el contrario, un problema filosófico es un enredo conceptual que resulta de alguna clase de incomprensión. En este sentido, es una investigación filosófica que cada uno debe realizar por y en sí mismo para descubrir el origen de tal incomprensión o confusión.

Las diferencias entre Sexto y Wittgenstein recién planteadas parecen matizarse en la última sección del libro III de las Hipotiposis, titulada "por qué el escéptico a veces aduce deliberadamente para persuadir argumentos débiles", en donde se expone cómo el pirrónico realiza la elección de los fármacos (argumentos) más débiles y suaves que de forma gradual pueden aumentar en su grado de sofisticación dependiendo de la gravedad del paciente "el que se inclina por la skepsis no duda en persuadir con argumentos ya sea vigorosos, ya sea, de modo deliberado, aparentemente más débiles, en cuanto le bastan muchas veces para alcanzar lo que se propone" (HP III. 280-81). Aquí Sexto amplía el espectro de recursos contra el dogmático y admite medios persuasivos — no sólo argumentativos. Pero la persuasión sigue estando al servicio de la suspensión del juicio. De esta forma, se utilizan diferentes fórmulas argumentativo-persuasivas en un escenario dialéctico para lograr la abstención; la elección de la clase de fórmula que se ha de utilizar depende siempre de qué tipo de afirmación realice primero el oponente. De otro modo, el pirronismo de Sexto resulta parasitario del dogmatismo, asume una estrategia defensiva. En Wittgenstein la persuasión asume el rol crítico de operar sobre el modo de entender los problemas filosóficos. En este sentido, la estrategia es de ataque directo.

con el modo de proceder del psicoanálisis que "no permite descubrir la causa, sino solamente la razón, por ejemplo, de la risa (...) el psicoanálisis tiene éxito sólo si el paciente está de acuerdo con la explicación ofrecida por el analista" ( $c f$. Moore, 1984, p. 315). Así también en Big Typescript insiste en esta analogía "no podemos, sin embargo, convencer a otro de un error a no ser que él (...) reconozca (realmente) esta expresión como la expresión correcta de su sentimiento. Es decir, sólo si él la reconoce como tal, es la expresión correcta. (Psicoanálisis)" (Wittgenstein, 1992, p. 11). 
Así, la labor filosófica wittgensteiniana sólo puede consistir en desarmar o desarticular la problemática misma, no en tratar de construir una respuesta, la cual puede revestir la forma de una teoría. Sólo gracias a la investigación gramatical estaremos en posición de ver o de entender por qué (en un sentido no causal) y cómo se gestó el problema y, al mismo tiempo, por qué dicha cuestión no debió, en primer lugar, haberse generado. Ahora bien, no hay tal cosa como aclaración completa, como una "curación total", aquello que se logra por medio del análisis gramatical es ver con mayor claridad pero la labor de investigación no tiene un punto final:

Lo que hace que un objeto sea difícilmente comprensible no es — cuando es significativo, importante- que exija cualquier instrucción especial sobre cosas abstrusas para su comprensión, sino la oposición entre la comprensión del objeto y aquello que quiere ver la mayoría de los hombres. Precisamente por ello puede ser lo cercano más difícilmente comprensible. Lo que hay que vencer no es una dificultad del entendimiento sino de la voluntad (CV $\S 91){ }^{16}$

Lo que el enfoque de Wittgenstein propone al acentuar la persuasión no es una propuesta "irracionalista", sino una nueva perspectiva sobre la función de los argumentos filosóficos. Aunque muchas veces la pretensión de los filósofos sea que sus argumentos refuten de manera conclusiva las tesis de un oponente, en la práctica tienen una función más bien exploratoria: ponen de manifiesto, en ocasiones de manera sorpresiva para su oponente, que ciertas creencias plausibles son contrarias a una tesis dada por lo que deben darse nuevos modos de restituir la coherencia en su sistema de creencias ( $c f$. Arroyo, 2014, p. 30).

De este modo, pueden plantearse diferencias en los modos de proceder filosóficos de Wittgenstein y los pirrónicos sextianos. La divergencia queda establecida por las exigencias y condiciones que fijan para el juego de dar y pedir razones. Mientras el pirrónico ejerce una operación corrosiva al interior del escenario argumentativo-dialéctico del dogmático e impulsa la suspensión del juicio, Wittgenstein disputa las condiciones exigidas por el dogmatismo a través de diferentes estrategias argumentativa-persuasivas. Por otra parte, es importante destacar que existe una larga tradición escéptica no-pirrónica en la que la persuasión

16 En Movimientos del pensar anota el 8-2-1931: "La tarea de la filosofía es tranquilizar el espíritu con respecto a preguntas carentes de significado. Quien no es propenso a tales preguntas no necesita la filosofía" (Wittgenstein, 2009, p. 221). Tiempo después, el 6-5-1931: "en la vida, como en la filosofía, nos seducen aparentes analogías (con lo que otro hace o puede hacer). Y también aquí hay un solo medio contra esa seducción: hacer caso a las suaves voces que nos dicen que aquí las cosas no son como alli'" (Wittgenstein, 2009, p. 233). 
tiene lugar destacado. Los académicos, especialmente con la promoción de Carnéades desarrollaron las críticas dirigidas al estoicismo en base a la crítica del razonamiento y de la conjetura y atenuaron el alcance de la suspensión del juicio. ${ }^{17}$ Las afinidades entre este proceder escéptico-persuasivo y los de Wittgenstein exceden los límites de este trabajo.

Esperamos que el desarrollo de este trabajo deje establecidas algunas diferencias ya esbozadas en las páginas iniciales de este trabajo sobre las condiciones que demanda la postulación de la suspensión del juicio pirrónica: 1- la disputa filosófica para Wittgenstein no siempre se establece en un escenario estable de argumentación dialéctica que deriva en la abstención. Al no exigirse ese escenario, da lugar a un sinfín de estrategias persuasivas para lograr que el oponente modifique su modo de entender su dificultad. Como consecuencia, al no restringir las disputas filosóficas a escenarios dogmáticos de argumentación dialéctica no renuncia a la práctica argumentativa ya que, desde una mirada más amplia, no reduce la función de los argumentos sólo a una práctica refutatoria; 2- Wittgenstein, a diferencia del pirrónico, no demanda un criterio de verdad para enfrentar los desacuerdos. Demanda más bien criterios lingüísticos para determinar si los problemas tienen sentido o no. No habría suspensión del juicio, sino disolución de problemas; 3- si bien ambas orientaciones filosóficas cabe describirlas como terapéuticas, la antigua todavía está ligada a una concepción de la filosofía como la búsqueda de la verdad. En el caso de Wittgenstein su terapéutica, más ligada a su lectura crítica de algunos textos de Freud (ver nota 15), entiende que la filosofía se relaciona, en gran medida,

17 El término técnico de Carnéades, que tomo prestado de los estoicos, es phantasía pithané, el cual se traduce, siguiendo la tradición inaugurada por Cicerón como "representación probable". Tal traducción, sin embargo, puede llevar a malentendidos ya que probabilidad para nosotros no tiene el mismo sentido que tenía para Cicerón. En una revisión histórica de tal traducción, observamos que se tradujo pithanê por probabilis, de probare; pithane tiene el mismo radical que peitho, que es persuadir; y probare es aprobar, aceptar. Así, la representación probabilis es aquella que aprobamos o aceptamos puesto que nos persuade. La mejor traducción sería "representación persuasiva", una vez que, para nosotros, probabilidad tiene una connotación matematizante que no se encuentra en Carnéades ( $c f$. Smith, 2007, p. 110). Otra consecuencia de esta teoría es la aparente contradicción que parece tener con la epoché, pues parece evidente que suspender el juicio es contrario a cualquier asentimiento, aunque éste sea solamente sobre lo aparente y no sobre lo absoluto. En este punto existe cierto desacuerdo entre Arcesilao y Carnéades con la "suspensión del juicio". De esta opinión participa Cicerón cuando dice que Arcesilao se mantuvo más firmemente en la epoché que Carnéades, pues éste llegó a reconocer que el sabio opinará, esto es, caerá en el error si es necesario, ya que en aquellos casos de declaraciones probables el sabio tendrá que asentir, aunque sea de modo parcial y fragmentado (cf. Cicerón, 1990, II, XLVIII, 148 y II, IV, 12). 
con la fascinación que ciertas imágenes y ciertos usos lingüísticos ejercen sobre nuestra voluntad, de ahí el peso otorgado a la noción de persuasión. De este modo, cambia la forma de interpretar el origen de los problemas filosóficos: derivan más de la seducción que nos producen ciertas confusiones o enredos lingüísticos que de argumentaciones erróneas, débiles o precipitadas. Finalmente, si entendemos de un modo general el escepticismo no como la negación del conocimiento en su variante moderna sino como una orientación filosófica que combate el dogmatismo, Wittgenstein y Sexto pueden ser aproximados. No obstante, debe destacarse, como he intentado plasmar en este texto a través del tratamiento diferenciado del desacuerdo, el lugar otorgado a la suspensión del juicio y la persuasión, la originalidad que cabe a cada una de estas dos terapéuticas filosóficas.

\section{Referencias}

Arroyo, G. (2014). Argumentar en contextos de desacuerdos últimos: el caso de la filosofía. En Arroyo, G., Matienzo, T. y Marafioti, R. (Eds). Explorando el desacuerdo epistemología, cognición y sociedad (pp. 17-32). Buenos Aires, Argentina: Editorial UNGS.

Arroyo, G., Matienzo, T. \& Marafioti, R. (2014). Explorando el desacuerdo epistemología, cognición y sociedad. Buenos Aires: Editorial UNGS.

Baker, G. (2004). Wittgenstein's method: neglected aspects: essays on Wittgenstein. Oxford: Blackwell Publishing.

Barnes, J. (1998). The Beliefs of a Pyrrhonists. En M. Burnyeat \& M. Frede (Eds.). The Original Sceptics: A Controversy (pp. 58-91). Indianapolis: Hackett Publishing Company.

Burdman, F. (2016). ¡No pienses, mira!: aspectos, persuasión y filosofía en Wittgenstein. Tópicos, 31, 0-21. Disponible en: http://www.scielo.org.ar/scielo.php?script=sci_arttext\&pid=S1666485X2016000100001

Burnyeat, M. (1998). Can the Sceptic live His Scepticism? En M. Burnyeat \& M. Frede (Eds.), The Original Sceptics: A Controversy (pp. 22-57). Indianapolis: Hackett Publishing Company.

Bouveresse, J. (2004). Filosofía, mitología y seudo-ciencia. Wittgenstein lector de Freud. Madrid: Síntesis.

Cicerón, M. T. (1990). Cuestiones Académicas. México: UNAM.

Frede, M. (1998). The Sceptic's Beliefs. En The Original Sceptics: A Controversy. (pp. 1-24). Indianapolis: Hackett Publishing Company.

Frede, M. (1998). The Sceptic's Two Kinds of Assent and the Question of the Possibility of Knowledge. En M. Burnyeat \& M. Frede (Eds.), The Original Sceptics: A Controversy (pp. 127-151). Indianapolis: Hackett Publishing Company.

Fogelin, R. J. (1981). Wittgenstein and Classical Skepticism. International Philosophical Quarterly, 21, 3-15. 
Fogelin, R. J. (1985). The Logic of Deep Disagreements. Informal Logic, 7, 1-8.

Fogelin, R. J. (1987). Wittgenstein and the History of Philosophy. En Wittgenstein (pp. 226-234). New York: Routledge \& Kegan Paul Ltd.

Fogelin, R. J. (1994). Pyrrhonian Reflections on Knowledge and Justification, Oxford: Oxford University Press.

Fogelin, R. J. (2004). The Skeptics are Coming! The Skeptics are Coming! En W. SinnottArmstrong (Ed.), Pyrrhonian Skepticism (pp. 161-73). Oxford: Oxford University Press.

Lammenranta, M. (2016). Skepticism and Disagreement. En D. Machuca (Ed.), Ancient Pyrrhonism and its Influence on Modern and Contemporary Philosophy (pp. 46-65), Berlin: Springer.

Machuca, D. (2013). Disagreement and Skepticism. New York and London: Routledge.

Marcondes de Souza Filho, D. (1996). Finding One's way About: High Windows, Narrow Chimmeys, and Open Doors. Wittgenstein's "Scepticism” and philosophical Method. En R. Popkin (Ed.), Scepticism in the History of Philosophy. A Pan-American Dialogue (pp. 167-179). Netherlands: Kluwer Academic Publishers.

Meléndez, R. (2003). Persuasión en el pensamiento tardío de Wittgenstein. En A. Flórez, M. Holguín, \& R. Meléndez (Eds.), Del Espejo a las Herramientas. Ensayos sobre el pensamiento de Wittgenstein (pp. 183-198). Bogotá: Universidad Nacional de Colombia.

Moore, G. E. (1984). Conferencias de Wittgenstein de 1930-1933. En Defensa del sentido común y otros ensayos (pp. 255-321). Madrid: Orbis.

Pritchard, D. H. (2005). Wittgenstein's On Certainty and Contemporary Anti-Scepticism. En D. Moyal-Sharrock \& W. H. Brenner (Eds.), Investigating On Certainty: Essays on Wittgenstein's Last Work (pp. 189-224). London: Palgrave Macmillan.

Pritchard, D. H. (2016). Wittgensteinian Pyrrhonism. En D. Machuca (Ed.), New Essays on Pyrrhonian Scepticism. Articulo disponible en Academia.edu: https://www.academia. edu/19856083/Wittgensteinian_Pyrrhonism

Porchat, O. (1991). Sobre o que aparece. Revista Latinoamericana de Filosofia, 17(2), 195-229.

Sexto Empírico. (1996). Hipotiposis pirrónicas. Madrid: Akal.

Sluga, H. (2004). Wittgenstein and Pyrrhonism. En W. Sinnott-Armstrong (Ed.), Pyrrhonian Skepticism (pp. 99-117). Oxford: Oxford University Press.

Smith, P. (1993). Wittgenstein e o pirronismo: sobre a natureza da filosofía. Analytica, 1(1), 153-186.

Smith, P. J. (2007). Hume y el escepticismo antiguo, Signos Filosóficos, 9, 105-126.

Wittgenstein, L. (1992). Filosofía [extracto de las secciones 86 al 93 de Big Typescript]. Revista de Filosofía, 5(7), 3-39.

Wittgenstein, L. (2009). Obra completa. Madrid: Gredos. 